\title{
Los conceptos de función administrativa y servicio público en la jurisprudencia y en la doctrina iuspublicista colombiana
}

\section{Ronald PACHECo Reyes ${ }^{1}$}

\section{RESUMEN}

La investigación identifica los argumentos de las principales tesis que equiparan o diferencian los conceptos de función administrativa y de servicio público en Colombia. Una tesis mayoritaria distingue el servicio público de la función administrativa asemejando esta última con prerrogativas públicas; una postura orgánica simplifica los servicios públicos al hacerlos depender de la calidad del prestador; y una perspectiva finalista, aunque presenta una alta coherencia, requiere de normas expresas para resolver aspectos procesales que surgen al entender que la función administrativa puede ser o no autoritativa y puede regirse o no por el derecho privado. Las inconsistencias teóricas resaltadas explican porqué es aún relevante estudiar los conceptos

1 Abogado de la Universidad Externado Colombia, Bogotá, Colombia. Doctorando en la Universidad Pompeu Fabra, Barcelona, España. Asesor en el Ministerio de Hacienda y Crédito Público. Correo-e: ronald.pacheco@uexternado.edu.co. Enlace ORCID: https:// orcid.org/0000-0002-6482-1700. Fecha de recepción: 25 de enero de 2021. Fecha de modificación: 15 de marzo de 2021. Fecha de aceptación: 10 de mayo de 2021. Para citar el artículo: PACHECO ReYes, RONALD, "Los conceptos de función administrativa y servicio público en la jurisprudencia y en la doctrina iuspublicista colombiana", Revista digital de Derecho Administrativo, Universidad Externado de Colombia, n. ${ }^{\circ} 26,2021$, pp. 11 48. DOI: https://doi.org/10.18601/21452946.n26.02. 
de servicio público y función administrativa, y aconsejan una actitud de prudencia frente a las generalizaciones comunes en el campo de los servicios públicos.

Palabras clave: función administrativa, servicios públicos, actividad económica, función pública, prerrogativas estatales.

\section{The Concepts of Administrative Function and Public Service in Colombian Judicial Rulings and Scholarly Works in Public Law}

\section{ABSTRACT}

The research identifies the arguments of the main thesis that either equate or differentiate the concepts of administrative function and public service in Colombia. A majoritarian thesis distinguishes public service from administrative function by resembling the later with public prerogatives; an organic position simplifies public services by making them dependent on the nature of the service provider, and a finalist perspective, although highly coherent, requires explicit rules to resolve procedural aspects that arise when understanding that the administrative function may or may not be authoritative and governed under private law. The theoretical inconsistencies highlighted explain why it is still relevant to study the concepts of public service and administrative function and advise caution against common generalizations in the field of public services.

Keywords: Administrative Function, Public Service, Economic Activity, Public Function, State Prerogatives.

\section{INTRODUCCIÓN}

¿De qué depende que las prestaciones de salud, educación, justicia, electricidad, acueducto, televisión, internet, juegos de suerte y azar, producción y venta de licores etc., sean jurídicamente calificados como actividades estatales, función administrativa ${ }^{2}$, servicios públicos o actividades económicas? La

2 En este escrito no se entrará en las indagaciones sobre la distinción o equiparación de los términos función administrativa y función ejecutiva. En todo caso, la indagación sobre estos y otros términos como potestad administrativa, ejercicio de poder y ejercicio de autoridad, entre otros, es materia de análisis por el autor en el marco de una investigación más 
historia del derecho enseña que la comprensión de tales actividades puede variar con el tiempo y en el espacio ${ }^{3}$, como es posible constatar en lo que se refiere al mundo europeo continental y demás regiones herederas de esta tradición $n^{4}$. En algunas épocas se consideró que prestar servicios públicos equivalía prácticamente a todo el quehacer estatal ${ }^{5}$, o que esta actividad correspondía con el objeto de la función administrativa ${ }^{6}$. En otros momentos se determinan alcances más específicos al concepto, vinculándolo a prestaciones desarrolladas en el marco de la función administrativa ${ }^{7}$, e incluso se opta por entender el servicio público como actividades económicas vinculadas con el Estado, no tanto como un servicio bajo su titularidad y organización, sino desde su compresión, como actuaciones en los mercados de agentes públicos o privados objeto de regulación, vigilancia y control estatal ${ }^{8}$. Este cambio en la comprensión del rol del Estado - de prestador a garante-implicará en ciertos

amplia que tiene dentro de sus objetivos ofrecer una propuesta de respuesta a la cuestión que se deja planteada en este escrito.

Lo señala en la presentación Alberto MONTAÑa Plata, Las transformaciones de la Administración pública y del derecho administrativo, t. I, Constitucionalización de la disciplina y evolución de la actividad administrativa. Homenaje al profesor Luciano Vandelli, Bogotá: Universidad Externado de Colombia, 2019. Frente al fenómeno administrativo lo hacía también MAsSimO S. Giannini, Derecho administrativo, vol. I, Madrid: Ministerio para las Administraciones Públicas, 1991, p. 95.

4 En Estados Unidos no se acogió el concepto de servicio público, las actividades bajo esta última rúbrica han sido desarrolladas por privados bajo reglas del libre mercado; $\sin$ embargo, preocupaciones similares a las europeas llevaron a doctrinas para intervenir tales actividades económicas. En el caso Munn vs. Illinois, "In 1877, the US Supreme Court upbeld the lower court's decision, thus establishing the principle that, when private businesses provide public services they are subject to public regulation (Farris and Sampson 1973, p. 23). In bis opinion on the Court's decision, Chief Justice Waite described grain storage as a business that was 'affected with the public interest.' It was, therefore, needful of regulation. Before long, other industries would also be determined to be 'in the public interest,' and brought under federal or state regulation". DAVID MCNABB, Public Utilities, Cheltenham: Edward Elgar, 2005, p. 10.

5 LEON Duguit, Las transformaciones del derecho público, Madrid: Francisco Beltrán, 1926, especialmente, pp. 100 y ss.

6 Señalaba Hauriou: "La fonction administrative a pour objet de pourvoir par des actes et par des opérations, à la fois juridiques et tecbniques, à la satisfaction des besoins publics et à la gestion des services publics". Maurice Hauriou, Précis de droit administratif et de droit public, 8. ${ }^{a}$ ed., París: Sirley, 1914, p. 9.

7 En Alemania se desarrolló el concepto de Daseinsvorsorge, entendido por la doctrina administrativista en idioma castellano como "procura existencial". ERNST FORSTHOFF, Tratado de derecho administrativo, Madrid: Instituto de Estudios Políticos, 1958.

8 Pierre Bauby et al., "Introducción general", en Pierre Bauby, Henri Coing y Alain de Toledo, Los servicios públicos en Europa. Hacia una regulación democrática, Bogotá: Universidad Externado de Colombia, 2010, pp. 25 y ss. 
contextos la pérdida de prevalencia de la expresión "servicios públicos" pero en otros escenarios la institución aún conservará un rol protagónico ${ }^{10}$.

Un esquema como el anterior parece dejar una especie de idea evolutiva en la que, en alguna época, los conceptos de función administrativa y de servicio público mantuvieron una estrecha cercanía -principalmente una relación intercambiable de género/especie-que progresivamente se fue perdiendo en la medida en que el mercado fue ganando territorio dentro de los Estados y absorbiendo la actividad de servicios públicos. Esta idea podría encontrar correlación con el modelo de servicios públicos acogido en su momento en la Unión Europea ${ }^{11}$, e incluso con el adoptado por la Constitución Política colombiana ${ }^{12}$. De hecho, puede decirse que la comprensión de los servicios públicos como una figura distinta de la función administrativa es la que se considera mayoritariamente acogida en el derecho colombiano ${ }^{13}$, especialmente a partir de algunas sentencias hito tanto de la Corte Constitucional ${ }^{14}$ como del Consejo de Estado ${ }^{15}$.

9 HeIKE SCHWEITZER, "Services of General Economic Interest: European Law's Impact on the Role of Markets and of Member States", en Marise Cremona, Market Integration and Public Services in the European Union, Oxford: Oxford University Press, 2011, pp. 11 y ss.

10 El modelo constitucional colombiano acogido en 1991 para los servicios públicos se inspira en las mismas ideas generales de liberalización que llevaron al derecho europeo a construir nociones como las de "servicios de interés económico general" y "servicios de interés general"; no obstante, mantuvo el concepto de servicio público como institución esencial. En todo caso, las múltiples comprensiones que a lo largo del tiempo ha tenido el concepto de servicio público ha llevado a algunos autores a sostener que para acabar con esta variedad de significados que dificultan la seguridad jurídica -o por lo menos la unidad de criterio- en este sector, una buena opción consistiría en eliminar el mencionado concepto. Cfr. Juan Pablo CajaRville, "Hauriou, Duguit y la noción de servicio público en el derecho público uruguayo", en Andry Mantilla Correa, Jaime Orlando Santofimio Gamboa y Héctor Santaella Quintero (coords.), Ensayos de derecho público. En memoria de Maurice Hauriou, Bogotá: Universidad Externado de Colombia, 2013.

11 TOMÁs-RAmÓn FernándeZ, "Del servicio público a la liberalización desde 1950 hasta hoy", Revista de Administración Pública, n. ${ }^{\circ} 150,1999$, pp. 57-73.

12 Véase artículos 333 y siguientes de la Constitución Política.

13 Cfr. Bernardo Carvajal Sánchez, "Avatares del servicio público en el derecho administrativo colombiano", en Las transformaciones de la administración pública y del derecho administrativo, t. I, Constitucionalización de la disciplina y evolución de la actividad administrativa. Homenaje al profesor Luciano Vandelli, Bogotá: Universidad Externado de Colombia, 2019. También se identifica esta postura mayoritaria en Daniel Castaño PARRA, "Estudio introductorio", en Alberto Montaña Plata y Daniel Castaño Parra (comps.), Régimen normativo de los servicios públicos domiciliarios: Ley 142 de 1994, disposiciones complementarias y jurisprudencia de constitucionalidad concordada, Bogotá: Universidad Externado de Colombia, 2010, p. 32.

14 Sentencia C-037 de enero de 2003

15 Sentencia de la Sección Tercera del Consejo de Estado, del 17 de febrero de 2005 radicación 50001-23-31-000-2003-00277-01(27673). 
A partir de este acuerdo general que parece existir en torno a la comprensión diferenciada de los conceptos de función administrativa y de servicio público, este artículo analizará los argumentos mediante los cuales la jurisprudencia constitucional y administrativa, y la doctrina iuspublicista colombiana sustentan la referida diferenciación conceptual, teniendo en cuenta, además, los argumentos de autores que niegan tal diferencia ${ }^{16}$.

En concreto, se indagará de qué manera la jurisprudencia y la doctrina iuspublicista colombiana organizan sus argumentos para concluir que los servicios públicos son distintos de la función administrativa, e igual proceder se aplicará respecto de la tesis que niega tal distinción. Esta indagación busca determinar si en la resolución de casos particulares -y en las posiciones doctrinales- que operan con los conceptos aludidos, se toma el modelo constitucional de servicios públicos como una variante que debe tenerse en cuenta en el proceso de argumentación, revisión de los hechos y decisión jurídica, sin perjuicio de que el resultado del proceso coincida o no con el modelo, o si el modelo constitucional es una premisa a la que debe llegarse a toda costa. Para ponerlo a manera de pregunta: ¿son coherentes las posiciones doctrinales que abordan la relación función administrativa y servicios públicos en Colombia?

Desde un punto de vista más general, lo anterior significa preguntarse por la coherencia interna de las posiciones teóricas sobre la relación de distinción o indistinción entre la función administrativa y los servicios públicos. La coherencia interna es considerada en este escrito un estándar relevante dentro de los sistemas jurídicos modernos, en la medida en que contribuye a dotar de algún tipo de racionalidad al derecho y además evita que los intereses políticos o económicos se impongan en la sociedad sin previo procesamiento jurídico ${ }^{17}$.

16 Se utiliza la etiqueta "doctrina iuspublicista colombiana" para hacer referencia a las obras más citadas por la jurisprudencia constitucional y administrativa en el momento de abordar la relación conceptual estudiada en este escrito. Aunque son múltiples las obras que han trabajado este asunto, el numeral 1.2 de este escrito permite identificar las mencionadas obras jurídicas.

17 La coherencia interna de las posturas jurídicas se preocupa por la existencia de conceptos jurídicos previos, derechos adquiridos y coordinación de los diversos intereses jurídicos presentes en la sociedad. La coherencia interna de las posturas teóricas se estudia dentro de las funciones de la dogmática jurídica. Al respecto, cfr. NIKLAS LuHManN, El derecho de la sociedad, México: Herder 2016; del mismo autor una visión inicial y más concreta: NiKLAS LuHMANN, Sistema jurídico y dogmática jurídica, Madrid: Centro de Estudios Constitucionales, 1983. Sobre dogmática jurídica en general (bajo la tradición sujeto-objeto), cfr. EBERHARD SCHMIDT-ASSMANN, La teoría general del derecho administrativo como sistema, Madrid: Marcial Pons, 2003; MANUel ATIENZA, Las razones del derecho. Teorías de la argumentación jurídica, México: Universidad Nacional Autónoma de México, 2005; Robert Alexy, Teoría de la argumentación jurídica, Lima: Palestra, 2007. 
Para cumplir con el objetivo propuesto, en la primera parte de este trabajo se revisarán las diversas posiciones de la jurisprudencia y la doctrina colombiana sobre la relación entre los conceptos de función administrativa y de servicio público (1), para lo cual se describirán tres de las principales posiciones que al respecto se han planteado en las últimas tres décadas $\mathrm{y}_{\text {, }}$ se identificará la tesis que se considera mayoritaria $(1.2)_{i}$ aunque antes de ello, será necesario exponer algunas aclaraciones sobre el concepto de función pública debido a que frecuentemente se equipara o se distingue de los conceptos de función administrativa y de servicio público (1.1). Esta revisión permitirá pasar a una segunda parte, en la que se plantearán algunas reflexiones sobre las tesis que abordan la relación entre los conceptos de función administrativa y de servicio público (2), las cuales se sustentan en observaciones que derivan de la estructura argumentativa de las propuestas teóricas analizadas (2.1) y en las dudas que emergen del análisis entrecruzado entre estas posturas (2.2), ambas, cuestiones que demuestran la importancia de continuar desarrollos académicos en esta materia.

\section{LAS DIVERSAS POSICIONES DE LA JURISPRUDENCIA Y LA DOCTRINA SOBRE LA RELACIÓN DE LOS CONCEPTOS FUNCIÓN ADMINISTRATIVA Y SERVICIO PÚBLICO}

Pese a que la Constitución Política y varias leyes sobre el sector público utilizan los conceptos de función administrativa y de servicio público como elementos clave para orientar el desarrollo de actividades tales como el ejercicio del poder público, la prestación de servicios de interés para la colectividad y la garantía de la libertad de empresa, no es del todo claro qué significan y cómo se relacionan estos conceptos en el derecho nacional ${ }^{18}$. La tarea de ofrecer claridad sobre estas dos nociones y su interacción ha estado en cabeza de la doctrina y de la jurisprudencia de la Corte Constitucional y del Consejo de Estado ${ }^{19}$.

La coherencia jurídica además ha sido considerada un atributo propio del derecho moderno, abordado bajo la idea de "sistema jurídico". Sobre los modelos de sistema jurídico más conocidos, véase Juan Manuel Pérez Bermejo, Coberencia y sistema jurídico, Madrid: Marcial Pons, 2006.

18 Un ejemplo del uso de estas nociones se observa en el artículo 70 de la Ley 489 de 1998, que establece que los "establecimientos públicos son organismos encargados principalmente de atender funciones administrativas y de prestar servicios públicos conforme a las reglas del Derecho Público".

19 Véase sentencia C-037 de enero de 2003 de la Corte Constitucional y sentencia de la Sección Tercera del Consejo de Estado, de 17 de febrero de 2005, radicación 50001 23-31-000-2003-00277-01(27673). 
Para observar cómo se ha desarrollado este intento de claridad, se revisarán las distintas posiciones que mantienen la jurisprudencia y la doctrina iuspublicista colombiana ${ }^{20}$ sobre la relación de los conceptos función administrativa y servicio público, pero antes conviene una precisión conceptual relacionada con la noción de función pública debido a que -como se describirá- es usada de forma diversa en no pocas oportunidades por los operadores del derecho y por el ordenamiento jurídico mismo.

\subsection{Algunas aClaraciones Sobre el CONCEPto de FunCión pública}

La relación conceptual función administrativa/servicio público está interconectada con el concepto función pública. Con el ánimo de determinar cómo se articulan estas nociones, la jurisprudencia y la doctrina destacan un doble entendimiento del concepto de función pública: uno cercano al empleo público ${ }^{21}$ y otro ligado al ejercicio del poder estatal en sentido general ${ }^{22}$. Pero, aunque

20 Véase un estudio detallado sobre los conceptos de servicio público y de función administrativa en AlBERTO MONTAÑA PlATA, El concepto de servicio público en el derecho administrativo, Bogotá: Universidad Externado de Colombia, 2005. Del mismo autor, un estudio más concreto sobre los conceptos función pública, función administrativa y servicio público, en Alberto MONTAÑA Plata, Los grandes fallos de la jurisprudencia administrativa colombiana, Bogotá: Universidad Externado de Colombia, 2013. Recientemente, sobre estos mismos conceptos, cfr. GERMÁn LOZANO VILLEGAS, "La función administrativa ejercida por particulares en Colombia", en Entidades privadas colaboradoras de la administración, Valencia: Tirant lo Blanch, 2020.

21 Esta comprensión deriva de disposiciones constitucionales, como el artículo 122: "No habrá empleo público que no tenga funciones detalladas en ley o reglamento y para proveer los de carácter remunerado se requiere que estén contemplados en la respectiva planta y previstos sus emolumentos en el presupuesto correspondiente". En sentido similar, las leyes 909 de 2004 y 1952 de 2019.

22 El artículo 228 de la Constitución establece que la administración de justicia es una función pública, el artículo 267 de la misma norma señala que la vigilancia y el control fiscal son una función pública. La Corte Constitucional, al pronunciarse sobre la función notarial, sostuvo que el "servicio notarial es no solo un servicio público, sino que también es desarrollo de una función pública" (sentencia de la Corte Constitucional C-741 de 1998, de 2 de diciembre de 1998, expediente D-2139). El Consejo de Estado ha sostenido que "El manejo que generalmente se hace de la función pública se ha reducido exclusivamente al ámbito del derecho administrativo, para significar la relación que une al servidor público con la Administración, y en tal sentido entonces se entiende, con carácter totalmente restringido como, el conjunto de regímenes de administración laboral aplicables a las personas que prestan sus servicios al Estado, cuando es lo cierto que, el concepto de función pública tiene una connotación mucho mayor. En efecto, función pública es toda actividad ejercida por los órganos del Estado para la realización de sus fines y, excepcionalmente, por expresa delegación legal o por concesión, por parte de los particulares" (sentencia del Consejo de Estado, Sección Tercera, 5 de agosto de 1999, radicado ACU-798). En la doctrina italiana, explica Montaña, el término función se asimila a la noción de actividad administrativa. Cfr. AlBERTO 
se perfilen estas dos diversas perspectivas, es importante tener en cuenta que en ciertos niveles abstractos ambos sentidos de la función pública difícilmente pueden separarse ${ }^{23}$.

En todo caso, es posible plantear hipótesis para ilustrar los posibles usos del concepto. Por ejemplo, al legislador o a un operador jurídico le puede interesar si un efecto es -o no- el resultado de una acción imputable al Estado en general, no de un órgano público específico. En este evento puede ser adecuado el uso del concepto de función pública en sentido amplio, como acción del poder estatal ${ }^{24}$. En otras hipótesis, puede no haber duda del carácter estatal de una competencia, lo que se busca determinar es a cuál de los distintos órganos debe atribuirse tal competencia; por tal razón, en estos supuestos será relevante encontrar las diferencias entre la función pública, en sentido amplio, y otras funciones estatales. Un tercer supuesto relacionado con un contenido preciso es el uso equiparable al empleo público; acá, el concepto función pública sirve para identificar la actividad que desarrollan los servidores del Estado y el régimen al que se someten ${ }^{25}$.

Ahora, el hecho de que sea posible -y en cierta medida útil- identificar distintos usos del concepto de función pública, no debe llevar a desconocer la existencia de algunos casos que desafían estas separaciones nítidas y que, por el contrario, exigen una actitud rigurosa y una perspectiva sistémica de más de un concepto jurídico clave y del derecho administrativo en general. Estas dificultades justifican y requieren marcos de análisis que -más allá de los abordajes descriptivos del conjunto de entes de la Administración

Montaña Plata, El concepto de servicio público, p. 157. Esta concepción amplia de función pública no solo se entrecruza con el concepto de empleo público, sino que, bajo cierto contexto, también se imbrica con el concepto de servicio público. Al respecto sostiene Carvajal que bajo la idea-fuerza de servicio público en la época del Estado colombiano preponderantemente prestador, el servicio público podía resultar siendo "equivalente a 'función administrativa ejercida por los servidores públicos' o que correspondiese a la labor adelantada por cualquier entidad estatal". Citado por Bernardo CARVAJAL SÁNCHEZ, "Avatares del servicio público en el derecho administrativo colombiano".

23 "La función pública, entendida como 'el conjunto de tareas y de actividades que deben cumplir los diferentes órganos del Estado [...]', comprende también la determinación de las reglas básicas que rigen la relación de subordinación del servidor público con el Estado" (sentencia de la Corte Constitucional C-830 de 2001, de 8 de agosto de 2001, expediente D-3368)

24 El Código Penal (Ley 599 de 2000) utiliza el concepto de función pública como elemento de los tipos penales que caen bajo su órbita; en este sentido, no se distingue entre el ejercicio de funciones administrativas, legislativas o judiciales porque todas estas funciones son, para interés del derecho penal, funciones públicas.

25 La Ley 909 de 2004 utiliza el concepto función pública en esta precisa dirección. Para un desarrollo doctrinal en este sentido del concepto, cfr. JORGE IVÁN RINCÓN CÓRDOBA, Derecho administrativo laboral: Empleo público, sistema de carrera administrativa y derecho a la estabilidad laboral, Bogotá: Universidad Externado de Colombia, 2009. 
pública- planteen explicaciones para comprender la forma en la que el Estado se organiza como mecanismo para identificar propósitos, tareas, órganos, estructuras y herramientas para adaptarse a las realidades concretas de cada sociedad ${ }^{26}$.

Pero aún siendo conscientes de los distintos usos que pueda tener el concepto función pública en el derecho colombiano, se presentan dificultades adicionales, por un lado, cuando no hay acuerdo en el sistema jurídico sobre el significado de los conceptos que utilizan los operadores del derecho (v. g. función administrativa, función judicial, servicio público) y, por otro lado, cuando aparecen ciertas actividades complejas -como la prestación de servicios públicos- que por sí mismas ocasionan dudas respecto de su naturaleza jurídica. Sobre esto se ha cuestionado, cequivale la prestación de servicios públicos al ejercicio de función administrativa?

\subsection{LAS POSICIONES DE LA JURISPRUDENCIA Y LA DOCTRINA SOBRE LA RELACIÓN DE LOS CONCEPTOS FUNCIÓN ADMINISTRATIVA Y SERVICIO PÚBLICO, Y LA TESIS MAYORITARIA}

La pregunta anterior ha sido abordada desde tres perspectivas: la de la jurisprudencia constitucional (1.2.1), la de lo contencioso administrativa (1.2.2) y la perspectiva de la doctrina iusadministrativista (1.2.3). Acá, se describirán tales posturas aclarando que, en todo caso, no se modificará la forma en la que los conceptos (función pública y función administrativa) han sido utilizados por cada una de las perspectivas, razón por la cual es importante que no se pierda de vista la aclaración presentada en el numeral anterior.

En las providencias, tanto de la Corte Constitucional como del Consejo de Estado, es posible observar que se evidencia un uso de los conceptos función administrativa y función pública como sinónimos, con las consecuencias problemáticas que de ello pueden derivarse ${ }^{27}$. De otro lado, parece existir acuerdo sobre la presencia de un -denominado- nuevo concepto jurídico o modelo de servicio público en Colombia, distinto del servicio público "a la francesa" que, a su vez, se distingue del concepto de función administrativa. Aunque también se pueden ver algunas posiciones que parecen restarle claridad a este acuerdo.

26 Para ver avances en este sentido, cfr. JORGE IVÁn RinCÓN CÓRDOBA, La teoría de la organización administrativa en Colombia, Bogotá: Universidad Externado de Colombia, 2018.

27 Sobre este asunto, véase AlBerto Montaña Plata, Los grandes fallos de la jurisprudencia administrativa colombiana. 


\subsubsection{Posiciones de la Corte Constitucional ${ }^{28}$}

Aunque la Corte Constitucional al resolver casos que tienen que ver con la relación entre los conceptos de función administrativa y de servicios públicos sostiene que la tesis acogida en el ordenamiento jurídico colombiano es la que distingue ambos conceptos, es posible encontrar diversas posiciones, incluso coincidentes en el tiempo, en las se equiparan.

a. Posiciones en las que la función administrativa y la prestación de servicios públicos son equiparadas: A finales de los años noventa se observa una jurisprudencia ${ }^{29}$ formada a partir de casos relacionados con la protección de derechos fundamentales por medio de la acción de tutela por acciones de los prestadores de servicios públicos. La argumentación partió de entender que "Cuando en desarrollo del artículo 365 de la Constitución Nacional, el Estado le otorga a un particular la facultad de prestar un servicio público, coloca en manos de ese ente privado el ejercicio de una función de naturaleza pública, desde donde es posible amenazar o llegar a vulnerar el derecho de petición de otros particulares ${ }^{\prime \prime 30}$. Esta posición que justifica la procedencia de la tutela en el marco de la prestación de servicios públicos por la superioridad que adquiría el prestador de servicios, fue moderada en la sentencia C-378 de $2010^{[31]}$.

Dejando de lado el asunto de la tutela en el marco de la prestación de servicios públicos, en la sentencia C-574 de 15 de julio de 2003 se estudió una demanda en contra del artículo 112 de la Ley 788 de 2002, al considerarse que el deber de abrir la denominada cuenta única notarial violaba el principio de igualdad porque a otros particulares que prestan un servicio público la ley no les imponía el deber de abrir este tipo de cuenta. La Corte desestimó la demanda al considerar que los notarios ejercen una actividad que implica

28 Las sentencias fueron seleccionadas de los resultados que arrojó la consulta, en la página web de la Corte Constitucional (desde 1992 hasta 2021), de palabras clave "función administrativa", "función pública" y "servicios públicos" que aparecían vinculadas en conjunto en una misma providencia. También se tuvieron en cuenta las referencias hechas por varias obras académicas al respecto.

29 Pueden verse las sentencias de la Corte Constitucional T-001 de 16 de enero de 1998 expediente T-142712; T-617 de 28 de octubre de 1998, expediente T-169767; T-638 de 4 de noviembre de 1998, expediente T-179381; y también la sentencia T-693 de 1999, de 16 de septiembre de 1999, expediente T-220705.

30 Sentencia de la Corte Constitucional T-693 de 1999, de 16 de septiembre de 1999, expediente T-220705.

31 "Ahora bien, lo anterior no quiere significar que todo tipo de conducta del particular que presta un servicio público sea susceptible de ser enjuiciadas por vía de tutela, por cuanto solo lo serán aquellos actos que tengan la potencialidad de amenazar o afectar derechos de naturaleza fundamental y frente a los cuales no se vislumbren otros mecanismos de defensa judicial o los mismos resulten insuficientes ante la amenaza de un perjuicio irremediable, en los términos del artículo 86 del Estatuto Superior". 
no solo la prestación de un servicio público, sino además el desarrollo de una función pública, lo cual los distingue de las demás personas privadas que prestan un servicio público.

El 21 de julio de 2005, nuevamente en sede de tutela ${ }^{32}$, la Corte analizó si los derechos a la personalidad jurídica e igualdad en el acceso al sistema bancario fueron vulnerados al restringirse el otorgamiento de crédito a pastores de iglesia. En este caso, la Corte sostuvo que la actividad bancaria era un servicio público por estar involucrado un interés colectivo. Aclaró que "por el carácter de servicio público que tiene la actividad bancaria, es procedente formalmente la tutela contra las entidades que la desarrollen". Aunque no se aborda explícitamente la relación entre los conceptos de función administrativa y de servicio público, parece que la Corte abandona en este caso la distinción de los mismos, teniendo en cuenta que frente a su argumentación se aclaró un voto precisando que tal corporación ha definido que no toda actividad que tenga relación con el interés general (como la actividad financiera) es un servicio público, y que los conceptos de función pública y de servicio público son distintos.

En la sentencia C-957 de 14 de noviembre de 2007 se estudió una demanda en contra de una disposición de la Ley 1122 de 2007 que prorrogó el período de gerentes de empresas sociales del Estado. En este evento se consideró la actividad que prestan estas empresas como un servicio público y se asoció a esta argumentación el concepto de función pública en múltiples ocasiones. Se sostuvo, por ejemplo, que en el caso concreto se buscaba "un ejercicio de la función pública que se ajuste a los principios consagrados en el artículo 209 de la Constitución y las directrices constitucionales para la prestación del servicio público. En este sentido, los principios que determinan el acceso a la función pública son los de igualdad y mérito" ${ }^{\prime \prime 3}$.

En 2011, mediante la sentencia C-368 de 11 de mayo, se estudió el arancel judicial. La Corte encontró constitucional las normas demandadas argumentando que la administración de justicia no solo era un servicio público, sino que, además, era una función pública. Por tanto -concluyó la Corte--, los alegatos que equiparaban la función judicial con un servicio público ordinario son equivocados porque desconocen el carácter especial de tal servicio público y, por tanto, la procedencia de reglas especiales como la posibilidad de establecer el arancel judicial.

33 Un uso similar del concepto de función pública (cercano al empleo público) puede verse en las sentencias de la Corte Constitucional C-041 de 1995 de 9 de febrero de 1995, expediente D-796; C-474 de 1999, de 7 de julio de 1999, expediente D-2274; y C-109 de 2002, de 20 de febrero de 2002, expediente D-3562. 
b. Posiciones que distinguen la función administrativa de la prestación de servicios públicos: Una sentencia hito sobre la relación analizada es la C-037 de enero de $2003^{[34]}$, en la que se estudió una demanda contra varios artículos de la Ley 734 de 2003. Dentro de las disposiciones demandadas, el artículo 53 establecía un listado de particulares sometidos a un régimen disciplinario especial, entre los que estaban aquellos que cumplieran labores de interventoría en contratos estatales y quienes prestaran los servicios públicos contemplados en el artículo 366 de la Constitución. Se afirmó en la demanda que en ninguno de estos dos casos existía subordinación jerárquica entre el contratista o prestador de servicios, y la Administración, por lo que aquellos no eran destinatarios del régimen disciplinario contemplado en la ley demandada.

La Corte declaró la exequibilidad de la disposición que contenía el primer evento al considerar que, en desarrollo de labores de interventoría en contratos estatales, el particular contratista resulta investido de una función pública y por esta razón resultaría aplicable la ley disciplinaria. En el segundo evento, la Corte declaró la exequibilidad de la norma condicionando a que se interprete que el particular que preste un servicio público únicamente es disciplinable si ejerce una función pública que involucre potestades inherentes al Estado asignadas explícitamente por el legislador.

La Corte precisó que "la Constitución distingue claramente los conceptos de función pública y de servicio público y les asigna contenidos y ámbitos normativos diferentes que impiden asimilar dichas nociones, lo que implica específicamente que no se pueda confundir el ejercicio de función pública, con la prestación de servicios públicos [...]. El servicio público se manifiesta esencialmente en prestaciones a los particulares. La función pública se manifiesta, a través de otros mecanismos que requieren de las potestades públicas y que significan, en general, ejercicio de la autoridad inherente del Estado".

Recientemente, en la sentencia C-185 de 8 de mayo de 2019 se reiteró la argumentación anterior. Frente al servicio de bienestar familiar se señaló: "Al tratarse de un servicio público no cabe su asimilación con el concepto de función pública, pues no solo formalmente la Constitución los distingue y los somete a un régimen jurídico distinto, [...] sino que, materialmente, cuando se trata de un servicio público, [...] el propio Texto Superior permite su prestación directa por particulares (CP, art. 365), sin que por ello se entienda que las personas que concurren a su ejecución adquieren la condición de funcionarios públicos o se les otorga autoridad alguna para ejercer potestades públicas".

34 Sentencia referida en decisiones del Consejo de Estado, fundamento particular de la sentencia de la Sección Tercera del Consejo de Estado, de 17 de febrero de 2005, radicación 50001-23-31-000-2003-00277-01(27673). 


\subsubsection{Posiciones del Consejo de Estado}

Por regla general, el Consejo de Estado distingue el ejercicio de la función administrativa de la prestación de servicios públicos ${ }^{35}$, aunque en sus decisiones utiliza indistintamente los conceptos de función administrativa y función pública. En sus primeras providencias, el Consejo de Estado sostuvo que no toda prestación de servicios públicos implicaba el ejercicio de una función pública, a pesar de que, en ciertos casos, pueda haber convergencia entre estos fenómenos. Para distinguirlos destacó que "la Función Pública participa en todo caso del poder del Estado, y que es de carácter siempre jurídico, mientras que el servicio público es de carácter material y técnico y en muchas de sus manifestaciones no puede utilizar el poder público ${ }^{\prime \prime 3}$. En un fallo posterior, se resaltó la distinción entre las actividades mencionadas, pero se utilizó el concepto de función pública en un sentido amplio, destacando que esta era "toda actividad ejercida por los órganos del Estado para la realización de sus fines". En contraste con esta actividad, sostuvo que el servicio público era "aquella actividad organizada dirigida a satisfacer necesidades de interés general de manera regular y continua por parte del Estado, en forma directa o por particulares expresamente autorizados para ello, con sujeción a un régimen jurídico especial" ${ }^{137}$.

En el marco de una acción popular, la Sección Tercera del Consejo de Estado distinguió los conceptos de función administrativa y servicio público señalando que el modelo constitucional de servicios públicos acogido en 1991 parte de la superación de la concepción francesa de los servicios públicos, por lo tanto, estos ya no son asimilables a la "función pública". En esta providencia se sostuvo que a pesar de que la titularidad del servicio de alumbrado público es atribuida al municipio -el cual puede prestarlo directamente o a través de un tercero especializado por contrato- tal condición no convierte el servicio en "función administrativa"

35 No obstante, algunas investigaciones durante el periodo 1998-2004 en materia de acciones populares han llevado a sostener que "la teoría clásica de los servicios públicos de inspiración francesa, que se creía ya superada, sigue aún vigente". HERNÁN VERGARA MESA, "La función administrativa: una mirada desde el derecho colectivo al acceso y eficiente prestación de los servicios públicos", Estudios de Derecho, vol. 66, n. ${ }^{\circ} 148,2009$, pp. 121-143

36 Sentencia de la Sección Tercera del Consejo de Estado, de 5 de agosto de 1999, radicación ACU-798.

37 Sentencia de la Sección Quinta del Consejo de Estado, de 19 de febrero de 2004, radicación 25000-23-25-000-2003-1843-01(ACU).

38 Sentencia de la Sección Tercera del Consejo de Estado, de 13 de mayo de 2004, radicación 50001-23-31-000-2003-00020-01(AP). 
La misma sección del Consejo de Estado ${ }^{39}$ reiteró la distinción entre los conceptos de servicio público y función administrativa, insistiendo en la superación de la noción "francesa" de servicio público - asimilable a la función pública- que dio paso a una concepción económica en la que la prestación está sometida a un mercado intervenido. Señaló que los derechos colectivos involucrados en la prestación de los servicios públicos no aluden a la "función pública", sino a una actividad económica que, por envolver actividades inherentes a la finalidad social del Estado, exige su intervención mediante instrumentos de regulación y control; tal intervención no se sustenta en la "función administrativa", sino en los derechos propios de los consumidores y usuarios especialmente en lo relacionado con la calidad y precio del servicio.

Por último, dentro los pronunciamientos más destacados de esta corporación, se ha referenciado a la sentencia de 17 de febrero de $2005^{[40]}$. En esta ocasión, el Consejo de Estado resolvió un recurso de apelación en contra de una sentencia del Tribunal Contencioso Administrativo del Meta, que había rechazado una demanda de reparación directa en contra de Telecom porque, al tener esta la condición de empresa industrial y comercial del Estado y desarrollar actividades de la misma naturaleza, el asunto estaba sometido al derecho privado y, por tanto, a la jurisdicción ordinaria ${ }^{41}$. El Consejo de Estado aclaró que no existía norma expresa que determinara la jurisdicción competente para conocer las controversias derivadas de actividades de empresas industriales y comerciales del Estado ${ }^{42}$ y que, por ello, debía acudirse a la cláusula general de competencia de la jurisdicción contencioso administrativa de este momento, que disponía que dicha jurisdicción conocía de "las controversias y litigios administrativos originados en la actividad de las entidades públicas y de las demás personas privadas que desempeñen funciones propias de los distintos órganos del Estado ${ }^{\prime \prime 3}$. Existía entonces un

39 Sentencia de la Sección Tercera del Consejo de Estado, de 10 de febrero de 2005, radicación 25000-23-25-000-2003-00254-01(AP).

40 Sentencia de la Sección Tercera del Consejo de Estado, de 17 de febrero de 2005, radicación 50001-23-31-000-2003-00277-01(27673). Esta decisión ha sido incluida en una obra dedicada a los grandes fallos de esta jurisdicción. AlBerto MOnTAÑa Plata, Los grandes fallos de la jurisprudencia administrativa colombiana.

41 El fundamento de esta conclusión se sustentó en el artículo 85 de la Ley 489 de 1998 y en decisión de la misma corporación en el mismo sentido.

42 Anteriormente, el artículo 31 del Decreto 3130 de 1968 establecía que las controversias derivadas de la actividad comercial e industrial de las empresas industriales y comerciales del Estado eran conocidas por el juez ordinario, y las originadas en desarrollo de funciones públicas eran competencia de la jurisdicción de lo contencioso administrativo. El artículo 121 de la Ley 489 derogó esta norma sin disponer en su lugar nada al respecto. En la providencia, el Consejo de Estado explicó que en materia de controversias contractuales sí había algunas reglas aplicables.

43 Artículo 82 del entonces Código Contencioso Administrativo. 
criterio material que llevó al Consejo de Estado a tener que determinar si la prestación de los servicios públicos domiciliarios podía ser considerada como una "función pública", ya que la mera naturaleza de Telecom (criterio orgánico) no era suficiente para definir la jurisdicción competente. El Consejo de Estado confirmó la decisión de primera instancia y concluyó que "en ningún caso la prestación de servicios públicos puede ser considerada, en sí misma, como una función pública, y solamente aquellas actividades que las empresas prestadoras de servicios públicos ejerzan en desarrollo de prerrogativas propias del Estado, pueden ser consideradas como tales ${ }^{\prime \prime 4}$.

\subsubsection{Posiciones doctrinales}

Un asunto metodológicamente interesante para resaltar de la última providencia es el hecho de haber revisado las posiciones más relevantes de la doctrina sobre el asunto de la relación entre la función administrativa y los servicios públicos. A pesar de esto, obviamente, la doctrina ya se venía pronunciando sobre estos conceptos y su relación. En esta sentencia se destacaron tres posiciones doctrinales respecto de la citada relación conceptual que se utilizarán acá como materia de análisis ${ }^{45}$.

La primera posición doctrinal considera que a pesar de la liberalización y la vocación económica que asumieron los servicios públicos -a partir de la Constitución de 1991-, estos no perdieron su dimensión pública; por consiguiente, con su prestación se ejerce función administrativa ${ }^{46}$. La segunda posición doctrinal argumenta que la prestación de servicios públicos es "función pública" solo cuando es desarrollada por una entidad estatal, pues el artículo 365 constitucional habilitó tanto a entes públicos como a particulares para su prestación, "De modo que el particular que presta servicios públicos que no han sido objeto de publicatio praevia, por su cuenta y riesgo, no lo hace por descentralización, delegación y desconcentración de

44 En oportunidades posteriores, el Consejo de Estado ha mantenido esta posición. Al respecto, cfr. sentencia de la Sección Tercera del Consejo de Estado, de 15 de agosto de 2007, radicación 88001-23-31-000-2005-00004-01(AP); y sentencia de la Sección Cuarta del Consejo de Estado, de 30 de marzo de 2016, radicación 47001-23-31-0002011-00133-01(19960).

45 También identificadas en Alberto Montaña Plata y Daniel Castaño Parra (comps.), Régimen normativo de los servicios públicos domiciliarios, p. 29.

46 Se cita como exponente de esta comprensión, al profesor AlBerTo MONTAÑa Plata, "El régimen normativo de la responsabilidad contractual en los servicios públicos domiciliarios. Configuración teórica de las prerrogativas públicas y protección del capital en consideración con su destinación", en Memorias IV Jornadas de Derecho Constitucional Administrativo. El régimen de las libertades. La responsabilidad de la Administración pública, Bogotá: Universidad Externado de Colombia, 2003, pp. 599-600. También en AlBERTO Montaña Plata, El concepto de servicio público en el derecho administrativo, p. 216. 
funciones y no cumple función administrativa" ${ }^{147}$. La última de las posiciones sostiene que "No toda actuación del proveedor de los servicios lleva implícita la función pública. Únicamente cuando, en desarrollo de la ley, ejerce un acto de autoridad o coloca al usuario en relación de subordinación, nos encontramos en presencia de este tipo de actuación $n^{\prime \prime 48}$.

Se pueden resumir las conclusiones de las tres posiciones de la doctrina así: (1) la prestación de servicios públicos implica función administrativa ${ }_{i}(2)$ la prestación de los servicios públicos es función pública únicamente cuando es desarrollada por una entidad estatal ${ }^{49}{ }_{i}$ y (3) la prestación de servicios públicos no implica función administrativa, excepto en los casos en los que -en el marco de la prestación- se ejerzan prerrogativas estatales.

A pesar de que la identificación de estas tres posturas doctrinales por parte del Consejo de Estado puede contribuir a la comprensión de la tesis mediante la creación de tipologías, un análisis profundo siempre exige atender los detalles para evitar los riesgos de las equiparaciones simplificadas. Si se compara esta tipología con las diversas posturas jurisprudenciales descritas, puede ser cierto que existen coincidencias en los fundamentos y las conclusiones de ambas, pero no se debe ignorar que en cada una de las tesis hay ingredientes específicos que inciden en la interpretación de los fenómenos observados. Algunos ejemplos: se describió una jurisprudencia de la Corte Constitucional que consideraba la prestación de servicios una actividad de naturaleza pública ${ }^{50}$. Esto no quiere decir que tal posición sea idéntica a la primera postura doctrinal que considera que la prestación de servicios públicos implica el ejercicio de función administrativa. Es posible que exista semejanza en el resultado, pero los fundamentos son distintos ${ }^{51}$.

47 Se expone como autor representativo de esta tesis a Hugo Palacios Mejía, El derecho de los servicios públicos, Bogotá: Derecho Vigente, 1999, pp. 29-30, citado en la sentencia del Consejo de Estado de 17 de febrero de 2005.

48 Carlos Alberto Atehortúa Ríos, Servicios públicos domiciliarios, proveedores y régimen de controles, Bogotá: Universidad Externado de Colombia, 2006, pp. 46-47, citado en la Sentencia del Consejo de Estado, del 17 de febrero de 2005.

49 Sostiene Moreno que, junto con el autor de esta segunda posición doctrinal, planteó "la diferencia de los conceptos de función pública o administrativa y servicios públicos", y señaló que tanto la Corte Constitucional -mediante la sentencia C-037 de 2003-como el Consejo de Estado aceptaron tal diferencia. Luis Ferney Moreno, "Los servicios públicos y su permanencia como institución jurídica en Colombia", en Teoría de los servicios públicos. Lecturas seleccionadas, Bogotá: Universidad Externado de Colombia, 2018.

50 Cfr. sentencia de la Corte Constitucional T-693 de 1999 de 16 de septiembre de 1999 expediente T-220705.

51 El fundamento de la Corte Constitucional se relaciona con la superioridad que adquiere el privado prestador de servicios públicos por el hecho de estar en esa situación, mientras que la postura doctrinal hace énfasis en el carácter teleológico de la actividad de servicio público. 
Otro de los supuestos se relaciona con la jurisprudencia que considera que "función administrativa" y "servicios públicos" no son asimilables, salvo que en la prestación de estos se ejerzan prerrogativas estatales. Esta tesis se asemeja en su conclusión con las dos últimas posturas doctrinales, ya que ellas también distinguen ambos supuestos; sin embargo, la segunda tesis acoge un criterio -en términos del Consejo de Estado- orgánico que no se hace evidente en la postura jurisprudencial a la que se asimila parcialmente.

También es interesante notar que, aunque el reconocimiento de un nuevo modelo de servicios públicos consagrado en la Constitución de 1991 es un factor común en las argumentaciones tanto de la jurisprudencia como de la doctrina, las diversas tesis han llegado a conclusiones distintas partiendo de esa misma premisa constitucional.

Esta premisa constitucional es la materia sobre la que trabajan las posturas teóricas que, valga decir, tienen un enfoque eminentemente jurídico debido a que el asunto de los servicios públicos nació siendo una forma de explicar el poder del Estado ${ }^{52}$. Como se evidenció en la jurisprudencia examinada, se parte de una premisa: el carácter liberalizado que a partir de la Constitución de 1991 asumieron los servicios públicos, y se utiliza como premisa superior para analizar la validez de las normas que enjuician. Por parte de la doctrina -en donde hay mayor espacio para la argumentación- se vienen presentando enfoques jurídicos más comprehensivos que se acercan a los servicios públicos ofreciendo análisis que incorporan explicaciones elaboradas desde las ciencias económicas y políticas ${ }^{53}$.

\section{ALGUNAS REFLEXIONES SOBRE LAS TESIS QUE ABORDAN LA RELACIÓN ENTRE LOS CONCEPTOS FUNCIÓN ADMINISTRATIVA Y SERVICIO PÚBLICO}

Las posturas teóricas que estudian la relación conceptual entre función administrativa y servicio público responden a la necesidad de afrontar determinados

52 Una explicación del rol de los servicios públicos en el origen del derecho administrativo y su evolución, en Alberto Montaña Plata, El concepto de servicio público en el derecho administrativo, pp. 117 y ss.

53 Un análisis de este tipo sobre los servicios públicos domiciliario, llamados también en la obra "servicios basados en infraestructura", puede verse en FELIPE NúñEZ FORERO, Servicios públicos domiciliarios, telecomunicaciones e infraestructura (instituciones, regulación y competencia), Bogotá: Universidad Externado de Colombia, 2017, pp. 24-25. Recientemente, ANíBAL ZÁRATE, "La protección constitucional de la rivalidad en el mercado como interés de las actuaciones administrativas en materia económica", en Jorge Iván Rincón (ed.), Las transformaciones de la administración pública y el derecho administrativo, t. I, Constitucionalización de la disciplina y evolución de la actividad administrativa, Bogotá: Universidad Externado de Colombia, 2019. 
vacíos presentes en el derecho positivo colombiano. Según se vio, varias providencias de la Corte Constitucional y del Consejo de Estado afirman claridad respecto de la distinción (o no confusión) entre el ejercicio de la función administrativa y la prestación de servicios públicos, en otras palabras, afirman una tesis mayoritaria al respecto ${ }^{54}$. En todo caso, es interesante preguntarse si esta afirmación es, no solo el resultado de la onda expansiva que produjo la consagración jurídico-política de un nuevo modelo económico para Colombia, sino también una conclusión que se deriva de premisas teóricas coherentemente articuladas con nuestra realidad institucional.

$\mathrm{Si}$-por lo menos en el ambiente académico- las decisiones jurídicas todavía se consideran el resultado de razones que intentan resolver cierta clase de problemas sociales, es importante indagar por la coherencia interna de los argumentos en los que se sustenta la distinción entre los conceptos estudiados y las excepciones que tal distinción reconoce. Ignorar esta cuestión implicaría comprender las decisiones jurídicas como un resultado de antemano conocido al que debe acomodársele alguna argumentación. Esta inquietud no pretende desconocer la lógica de un sistema jurídico de derecho positivo legislado y considerado jerarquizado - en el que las órdenes de la Constitución deben cumplirse-, pero intenta llamar la atención sobre las condiciones que deben reunirse para que ese sistema pueda operar de forma armónica.

¿Cómo estar seguros de la distinción entre prestación de servicios públicos y ejercicio de función administrativa si ninguno de estos conceptos está previamente definido, ni tampoco existe acuerdo sobre el significado y alcance de tales conceptos?; cla consagración del nuevo modelo constitucional de servicios públicos implica la automática desaparición de servicios públicos configurados bajo otra lógica?; si siguen existiendo servicios públicos "a la francesa", ¿siguen siendo servicios públicos en los términos de la Constitución de 1991?; ¿qué los asemeja o diferencia?

Estas son tan solo algunas de las inquietudes que pretenden resaltar la importancia de tener claras las premisas sobre las cuales se fundamentan consecuencias jurídicas. Responder a estos interrogantes de forma detallada ameritaría un espacio que supera el disponible acá, pero es posible comenzar

54 Con claridad, la sentencia C-037 de 2003, de 28 de enero de 2003, expediente D-3982 y seguida en las sentencias del Consejo de Estado de 17 de febrero de 2005. Confirmada por la Corte Constitucional en la C-185 de 8 de mayo de 2019, expediente D-12890. También por el Departamento Administrativo de la Función Pública en el Concepto 51521 de 2020, Radicado n. ${ }^{\circ} 20206000051521$ de 11 de febrero de 2020. Destacando el contexto que resalta un tránsito que va del Estado prestador y empresario, al Estado regulador y garante, Carvajal sostiene que "la actividad consistente en la prestación de servicios no es una función administrativa que pueda entenderse como atributo esencial y prerrogativa del Estado". BERnARDo CARVAJAL SÁNCHEZ, "Avatares del servicio público en el derecho administrativo colombiano", op. cit. Véase también DanieL CAstaño Parra, "Estudio introductorio", op. cit., p. 32. 
la tarea planteando algunas observaciones que derivan de la estructura argumentativa de las propuestas teóricas analizadas (2.1), e identificando las dudas que emergen del análisis entrecruzado entre estas posturas (2.2).

\subsection{Algunas observaciones QUE DERIVAN DE LA ESTRUCTURA ARGUMENTATIVA DE LAS PROPUESTAS TEÓRICAS ANALIZADAS}

Se expondrán las tesis que subyacen a las propuestas de la jurisprudencia y de la doctrina identificadas, sin descuidar las diferencias que entre las mismas existen. Se resumirá la idea principal de cada unas de las propuestas, se plantearán observaciones a tales ideas con fundamento en las premisas que las soportan y se intentará dejar en evidencia algunas cuestiones de interés jurídico. A continuación, se abordarán las correspondientes posiciones teóricas en orden inverso al anteriormente expuesto, poniéndoles las etiquetas de tesis mayoritaria, orgánica y finalista, únicamente para facilitar la lectura.

\subsubsection{La prestación de servicios públicos no implica función administrativa, excepto en los casos en los que -en el marco de la prestación- se ejerzan prerrogativas estatales: tesis mayoritaria}

Esta posición distingue la función administrativa de la prestación de servicios públicos, en esencia, con fundamento en el siguiente argumento: a partir de la Constitución Política de 1991 existe un nuevo modelo de servicios públicos, distinto del anterior -francés ${ }^{55}-$, por consiguiente, función administrativa y servicio público son dos figuras con "contenidos y ámbitos normativos diferentes que impiden asimilar dichas nociones". Se dice que son distintas porque la prestación de servicios públicos, a diferencia de la función administrativa, es ahora una actividad económica que a pesar de su vínculo con una finalidad social se ejerce en condiciones de igualdad bajo un mismo régimen jurídico común. La Corte trata de ilustrar estas diferencias así: "El servicio público se manifiesta esencialmente en prestaciones a los particulares. La función pública se manifiesta, a través de otros mecanismos que requieren de las potestades públicas ${ }^{\prime \prime 5}$.

55 Afirmado en varias de las providencias descritas en el segundo apartado. Ante estas etiquetas que generalizan e idealizan fenómenos, no hay que olvidar que este llamado "modelo francés" ni siquiera en Francia era siempre verificable. BERnARDo CARVAJAL SÁnCHEZ, "Avatares del servicio público en el derecho administrativo colombiano". Además, señala Montaña, "en estricto sentido, la Escuela de Burdeos, no concibió a los servicios públicos como una función pública, sino como la justificación misma del Estado y del derecho administrativo". Alberto Montaña Plata, Fundamentos de Derecho administrativo, Bogotá: Universidad Externado de Colombia, 2010 [ebook].

56 Para corroborar esta explicación podría preguntarse: ¿no hay ejercicio de función 
Dentro de las consecuencias más notables de este modelo se encuentra la del régimen jurídico de la actividad de servicios públicos: el derecho privado. Como se trata de una actividad materialmente económica, desplegada en condiciones de libre mercado, que cualquiera puede desarrollar, no se justifican tratos diferenciados ni prerrogativas por la calidad del prestador. Ahora, cuando no se cumple la lógica argumentativa de esta tesis, es decir, cuando quienes presten servicios públicos no actúan en condiciones de igualdad, sino imponiéndose frente a otros sujetos, en tales casos -se sostiene-sí se ejerce función administrativa y procede un régimen de derecho público.

Este "modelo 1", que en adelante se calificará como el de la "tesis mayoritaria", se podría resumir así:

Regla general: servicios públicos + prestados por públicos o privados + sin prerrogativas: actividad económica en libre mercado = derecho privado

Excepción: servicios públicos + prestados por públicos o privados + con prerrogativas: función administrativa $=$ derecho público

Algunas dudas surgen de este modelo. Esta tesis sustenta la diferencia entre los dos conceptos en el ejercicio de prerrogativas estatales, las cuales se consideran normalmente desplegadas cuando se ejerce función administrativa. Ahora -y esta sería una primera observación a esta postura-, en las posturas que comparten este argumento, hay un uso indiscriminado de términos como "potestades inherentes al Estado", "potestades públicas", "autoridad inherente del Estado", "prerrogativas propias del Estado", "acto de autoridad" y "subordinación", pero no está claro a qué se refiere cada uno y si todos deben ser entendidos en idéntico sentido. Varias podrían ser las alternativas de entendimiento, entre estas: cualquier atribución estatal, atribuciones estatales que impliquen la potencialidad de imponerse sobre los ciudadanos, atribuciones estatales que impliquen el ejercicio de la fuerza, atribuciones estatales que impliquen un servicio a los ciudadanos, atribuciones estatales que impliquen la exclusión de razones privadas para actuar ${ }^{57}$, etc. Si se asumiera que el significado que pretenden expresar quienes utilizan todas

pública que se manifieste en prestaciones a los ciudadanos?, ¿no hay servicios públicos que requieren del ejercicio de potestades públicas?

57 En el derecho se discute sobre conceptos como los de autoridad, poder y coacción, dándoles diversos alcances. Cfr. JOSEPH RAZ, The Authority of Law. Essays on Law and Morality, Oxford: Clarendon Press, 1979; LESLIE GREEN, The authority of the State, Oxford: Clarendon Press, 1988; Herbert Hart, The Concept of Law, Oxford: Oxford University Press, 1994; ThOmas Christiano, "The Authority of Democracy", The Journal of Political Philosopby, vol. 12, n. ${ }^{\circ} 3,2004$, pp. 266-290; FABIEnNe Peter, "Political Legitimacy", The Stanford Encyclopedia of Pbilosopby, 2017. Recuperado de https://philpapers.org/rec/ petpl. Por tanto, no es preciso utilizarlos de forma indistinta para resolver problemas de las ciencias sociales. 
estas expresiones es aquel que se traduce en el ejercicio de facultades (de ordenar un deber ser) de imposición, incluso en contra de la voluntad de los ciudadanos, caben algunas dudas adicionales.

En varias providencias de la Corte Constitucional, algunas posteriores a la C-037 de 2003, se equiparó la función pública con la prestación de ciertos servicios públicos como la administración de justicia ${ }^{58}$, el servicio de notaría ${ }^{59}$, el bancario ${ }^{60}$ e incluso el prestado por algunas empresas sociales del Estado ${ }^{61}$. No obstante, la equiparación en estos casos no se fundamentó en el ejercicio de prerrogativas públicas, sino en el "carácter especial" que -en términos generales- se consideró que tenían dichas actividades.

Adicionalmente, este criterio de equiparación de conceptos mediante el ejercicio de prerrogativas estatales puede dar lugar a dudas en actividades de particulares o entes no públicos que tienen un carácter prestacional y que se brindan u ofrecen al público ${ }^{62}$. El hecho de que existan actividades que materialmente puedan ser similares a las actividades de servicios públicos y que incluyan el ejercicio de potestades estatales podría terminar incluyendo este supuesto de hecho bajo el ámbito argumentativo de esta postura teórica, a pesar de que tales actividades no son jurídicamente tratadas como servicios públicos.

Es posible evidenciar que varias de las inquietudes que genera la tesis mayoritaria obedecen a la asimilación de la función administrativa con el ejercicio de prerrogativas públicas; sin embargo, no aclara qué sucede cuando se ejerce una función administrativa que no involucre dicha característica ${ }^{63}$.

58 Sentencia C-368 de 2011, de 11 de mayo de 2011, expediente D-8245.

59 Sentencia C-574 de 2003, de 15 de julio de 2002, expediente D-4462.

60 Sentencia T-763 de 2005, de 21 de julio de 2005, expediente T-1079385.

61 Sentencia C-957 de 2007, de 14 de noviembre de 2007, expediente D-6813.

62 Manifiesta Santaella que "Hoy es común ver sujetos privados [...], desempeñando actividades públicas como la expedición de licencias de construcción o la emisión de certificados de gases indispensables para la circulación de vehículos", HÉCTOR SANTAELLA QUINTERO. "Algunas reflexiones sobre las nuevas formas de actuación administrativa impuestas por el mercado y la técnica y sus implicaciones para la metodología de la ciencia jurídica-administrativa", Revista digital de Derecho Administrativo, n. ${ }^{\circ}$ 5, 2011, pp. 87 105; o piénsese en la actividad de estandarización que ofrecen algunos organismos de normalización que aunque no se consideren coercitivos, indirectamente, terminan incidiendo en la voluntad de los ciudadanos, incluso de forma más efectiva que cuando se acude a la fuerza. HÉCTOR SANTAELLA QuinTERO, Normas técnicas y derecho en Colombia: Desafíos e implicaciones para el derecho en un entorno de riesgo, Bogotá: Universidad Externado de Colombia, 2008.

63 Al respecto, Montaña resalta que no todas las actividades del Estado implican el ejercicio de autoridad. Alberto Montaña Plata, El concepto de servicio público en el derecho administrativo, p. 214. 
Aunque la tesis mayoritaria -como las demás-inicia su argumentación con la liberalización de los servicios públicos, por regla general, sustenta la diferenciación de estos en la verificación -o no-del ejercicio prerrogativas estatales; lo que lleva a un argumento circular: la prestación de servicios públicos es función administrativa cuando en su prestación se ejerce función administrativa. A pesar de que la Corte Constitucional y el Consejo de Estado plantean como diferencia entre la prestación de servicios públicos y el ejercicio de función administrativa que en los primeros no se ejerce autoridad y en los segundos sí, tal argumento es insuficiente pues en ambas actividades se ejercen tantos actos autoritativos como no autoritativos ${ }^{64}$.

Otra cuestión que surge de este planteamiento es que se considera que el régimen jurídico para los servicios públicos será el derecho privado y excepcionalmente el derecho público cuando se verifique el ejercicio de prerrogativas. Sin embargo, hay casos en los cuales se aplica un régimen de derecho público sin que esté presente el ejercicio de aquellas. En los eventos en los que hay recursos públicos o servidores públicos involucrados en la prestación de los servicios es frecuente ver la presencia del derecho disciplinario, del control fiscal, del derecho presupuestal y, en algunos casos, del derecho de contratos estatales exigiendo la aplicación de principios de derecho público ${ }^{65}$. No queda claro entonces este modelo en los eventos en los que no se verifica el ejercicio de prerrogativas de poder y aun así procede el derecho público.

Podría entenderse que esta tesis intenta proponer una especie de naturaleza especial que ahora tienen los servicios públicos bajo el nuevo modelo constitucional y tratan de caracterizarse para confirmar tal naturaleza especial: son actividad económica, prestados en masa, consisten en prestaciones, implican el despliegue de técnica, son de interés general, se desarrollan en libre mercado, en condiciones de igualdad, tienen costo, están vigilados y regulados ${ }^{66}$. Esta es una lógica interesante, incluso, puede ser una primera manera de acercarse a esas actividades; sin embargo, hay algunos asuntos que no quedan claros. ¿Son las características que se le atribuyen a estos

65 En la Unión Europea, las regulaciones en materia contractual y presupuestal vienen teniendo importantes efectos en los ordenamientos jurídicos de los Estados miembros, asuntos relacionados con la ejecución de recursos públicos y sus cauces de contratación han tomado tanta o más importancia a nivel supraestatal que los clásicos conceptos de administración pública organizativos y funcionales. Al respecto, cfr. SiLVIA DíEZ SASTRE y Ester Marco PeÑas, "La convergencia de las reglas de contratación pública y disciplina presupuestaria en el sector público instrumental", Revista Española de Derecho Administrativo, n. ${ }^{\circ}$ 205, 2020; y José MARía GimenO Feliú, "Las fronteras del contrato público: Depuración conceptual de los negocios jurídicos excluidos desde la perspectiva funcional del derecho europeo", Revista Española de Derecho Administrativo, n. ${ }^{\circ} 205,2020$.

66 Un valioso esfuerzo de caracterización en Bernardo CARVAJAL SÁNCHEZ, "Avatares del servicio público en el derecho administrativo colombiano". 
servicios públicos taxativas o no?, ¿qué pasa cuando hay actividades estatales o netamente privadas que cumplen esas características, se convierten en servicios públicos?

Una última observación es que, en las providencias más representativas de esta postura ${ }^{67}$, se presenta un modelo de forma absoluta, y se sostiene: la prestación de servicios públicos no se puede confundir con el ejercicio de función administrativa. Sin embargo, cuando la realidad contradice esta afirmación, no queda más remedio que desconocer el absolutismo de la fórmula. Esta observación no apunta a problemas de redacción de la postura, ni siquiera a una posible vulneración del principio de no contradicción ${ }^{68}$ porque podrá interpretarse que este modelo lo que quiere decir es: por regla general, la prestación de servicios públicos no implica función administrativa, excepcionalmente, cuando se verifica el ejercicio de prerrogativas estatales, sí lo implica ${ }^{69}$. Para no violar el principio de no contradicción habría que esperar entonces que este modelo explique en qué casos y por qué razones la prestación de servicios públicos sí implica función administrativa. Esta postura responde: cuando se ejerzan prerrogativas públicas ${ }_{i}$ respuesta que, a su vez, indica una comprensión particular del concepto de función administrativa y que genera dudas.

La tesis mayoritaria no otorga importancia al hecho de que no siempre la ejecución de prerrogativas estatales implica el ejercicio de función administrativa y que no todo desarrollo de esta involucra el ejercicio de aquellas ${ }^{70}$. ¿Por qué razón esta postura identifica función administrativa con ejercicio de prerrogativas estatales? De sus argumentos es posible deducir una posible respuesta: porque cuando no se ejercen prerrogativas estatales, los servicios públicos se manifiestan materialmente como actividades económicas comerciales orientadas bajo un régimen jurídico y de control judicial que emerge sin dificultades: el derecho privado. Pero cuando aparecen las prerrogativas estatales, se descuadra la anterior ecuación. Con la experiencia que muestra que en el derecho colombiano las prerrogativas estatales han sido materia

67 Sentencia C-037 de 2003, de 28 de enero de 2003, expediente D-3982; y Consejo de Estado, Sección Tercera, de 17 de febrero de 2005, radicación 50001-23-31-000-200300277-01(27673).

68 Paula Gottlieb, "Aristotle on Non-contradiction", en The Stanford Encyclopedia of Pbilosopby, 2019. Recuperado de https://plato.stanford.edu/archives/spr2019/entries/ aristotle-noncontradiction/

69 De hecho, algunos autores así lo presentan. Carlos Alberto Atehortúa Ríos, Servicios públicos domiciliarios, proveedores y régimen de controles.

70 Tratando el asunto de las autorizaciones y las concesiones, Covilla señala que "ha sido superada ya la equivalencia entre prerrogativa pública y función administrativa". Juan Carlos Covilla Martínez, Autorizaciones y concesiones en el derecho administrativo colombiano, Bogotá: Universidad Externado de Colombia, 2014, p. 132. 
del régimen jurídico y del control judicial del derecho público, el puente que aparece a primera mano para unir la prestación de servicios públicos con el ejercicio de prerrogativas y con el régimen jurídico y de control judicial de derecho público, termina siendo: la función administrativa.

\subsubsection{La prestación de los servicios públicos es función administrativa únicamente cuando es desarrollada por una entidad estatal: la tesis orgánica}

Esta tesis concuerda con la tesis mayoritaria en cuanto considera que, en ciertos casos, la función administrativa y la prestación de servicios públicos pueden coincidir; sin embargo, se diferencia en el criterio que permite dicha convergencia. Mientras que para la tesis mayoritaria el criterio para considerar que la prestación de servicios públicos y la función administrativa coinciden es la verificación del ejercicio de prerrogativas públicas, para esta tesis, el criterio es orgánico, habrá convergencia si el servicio público es prestado por una entidad pública.

Este "modelo 2" que se denominará como la "tesis orgánica", podría formularse así:

Regla general: servicios públicos + prestados por privados: actividad comercial: no función administrativa $=$ derecho privado

Excepción: servicios públicos + prestados por públicos = actividad no comercial (función administrativa) $=$ derecho público

Esta postura doctrinal es interesante porque analiza la relación conceptual a partir de una estrategia que comienza delimitando jurídica y teleológicamente la función administrativa y el servicio público. La primera es una actividad que por mandato constitucional y legal se reserva a las autoridades y se desarrolla con base en los principios de igualdad, imparcialidad y publicidad para el beneficio colectivo. La segunda es una actividad normalmente dirigida "a proveer bienes privados, en las que puede obtenerse un beneficio patrimonial". Pareciera que esta tesis acude a un argumento material para distinguir estas dos instituciones, sin embargo, dicho estilo argumentativo se detiene cuando se enfrenta con la hipótesis de prestación de servicios públicos por parte de entes estatales. Los argumentos que hacían característico al servicio público en esta tesis -e incompatible con la función administrativa- dejan de tener importancia y el servicio público, inicialmente definido como una actividad comercial, al prestarse por una autoridad, solo puede ser considerado como una función pública al asumirse que las actividades económicas atienden al provecho particular, lo cual es - para esta postura-incompatible con la función administrativa. 
Una primera observación -ya destacada parcialmente por el Consejo de Estado- es que se hace depender la distinción o equiparación de la función administrativa y el servicio público de los sujetos que desarrollen tales actividades $^{71}$. Una segunda observación es que se considera incompatible el ejercicio de actividades económicas por parte del Estado, "la actividad de los comerciantes, en sí misma considerada, no puede ser parte de la función administrativa", sin embargo, no es claro cómo sería explicada desde tal postura, la presencia -bien establecida- de las formas estatales dedicadas a explotar actividades comerciales e industriales.

\subsubsection{La prestación de servicios públicos implica función administrativa: la tesis finalista}

Esta tesis se sustenta en una consistente estructura conceptual que articula, entre otras, nociones como función administrativa, actividad administrativa, actividad administrativa económica, acto administrativo y servicio público. Destaca dos características esenciales de la actividad de prestación de servicios públicos. En primer lugar, tiene un carácter teleológico que la vincula con fines estatales ${ }^{72} y$, en segundo lugar, consiste en un tipo de actividad que se desarrolla en el marco del fenómeno administrativo, que se manifiesta principalmente de manera no autoritativa ${ }^{73}$, aunque algunas veces, por los fines que persigue ${ }^{74}$, también puede expresarse autoritativamente. Este marco conceptual le permite argumentar que la prestación de servicios públicos implica el ejercicio de función administrativa ${ }^{75}$ y que, por su carácter especial (ni típica actividad administrativa ni mera actividad económica), se encuentra sometida a un régimen jurídico, también, especial.

71 Para un análisis crítico sobre el tratamiento doctrinal de los prestadores, véase ALBERTO Montaña Plata, "La desconfiguración del régimen jurídico de los servicios públicos domiciliarios a partir de la calificación de entidades públicas a las empresas de servicios públicos mixtas", Revista digital de Derecho Administrativo, n. ${ }^{\circ}$ 3, 2010, pp. 163-190.

72 Alberto Montaña Plata, El concepto de servicio público en el derecho administrativo, p. 183.

73 Ibid.

74 Ibid.

75 Esta postura fue acogida por el autor para sustentar la naturaleza jurídica que podría tener una actividad de comunicación audiovisual en Colombia. Se consideró la herramienta conceptual más viable debido a que esta interpretación no contradice el modelo constitucional de servicios públicos acogido en la Constitución Política. Esta visión permite el libre ejercicio de actividades económicas y al mismo garantiza los consecuentes efectos colectivos que la actividad audiovisual tiene sobre la sociedad, cuenten con herramientas que facilitan una intervención más garantista que la que ofrece un exclusivo libre mercado. RONALD PACHECO REYES, Televisión y nuevas realidades tecnológicas y de mercado. Hacia el sistema de la comunicación audiovisual, Bogotá: Universidad Externado de Colombia, 2017, p. 276. 
El "modelo 3" que subyace a esta postura, será calificado como la "tesis finalista" y podría expresarse así:

servicios públicos + actividad económica ligada a fines sociales + prestados por particulares o públicos: función administrativa $=$ derecho especial

A diferencia de la tesis mayoritaria, esta tesis estipula una noción de función administrativa para establecer un vínculo con el concepto de servicio público y con otros conceptos jurídicos. Esto le permite evidenciar que la función administrativa no solo se expresa mediante prerrogativas, sino también mediante actividades que no implican el desarrollo de estas atribuciones ${ }^{76}$. A diferencia de la tesis orgánica, no considera la prestación de servicios públicos como una mera actividad comercial, sino que además de su carácter económico los entiende como una actividad ligada a los fines sociales del Estado.

La principal observación que se le puede formular a esta tesis es que la jurisprudencia constitucional y administrativa no consideran que la prestación de los servicios públicos implique el ejercicio de función administrativa. Aunque, en estricto sentido, más que un problema de esta tesis se trata de su situación particular frente a lo que sostienen las referidas altas cortes y las otras posturas doctrinales. El Consejo de Estado argumentó que esta "tesis desconoce la manera en que el constituyente y el legislador concibieron el régimen de los servicios públicos" ${ }^{117}$, pero al analizar las razones del supuesto desconocimiento, es posible concluir que se debe al concepto que acoge de función administrativa (función pública en los términos de la providencia). En la sentencia se vincula el ejercicio de "funciones públicas" al ejercicio de prerrogativas públicas, pero no se tiene en cuenta que la tesis finalista, si bien reconoce que la función administrativa normalmente se manifiesta mediante el ejercicio de autoridad, también demuestra que hay casos en los que lo hace sin revestir tal condición.

Esta tesis, en comparación con las demás, es la que mayor coherencia interna evidencia al estar fundada en un marco conceptual articulado que no se observa contundentemente en las otras posturas, en otras palabras, no se limita en forma exclusiva al análisis del concepto de servicio público, sino

76 Considera esta tesis que entender la función administrativa en sentido restringido (identificada con los actos de poder) -enfrentada al servicio público-podría dar lugar a "una confusión entre la actividad que desarrolla la Administración y la forma como se concreta esta actividad", pues, por un lado, un asunto es la actividad material de servicio público y otro muy diferente la producción de actos administrativos; y por otro lado, en el servicio público pueden verificarse actos administrativos como actos que no involucran ejercicio de poder. AlberTo MONTAÑa Plata, El concepto de servicio público en el derecho administrativo, pp. 123 y 213.

77 Sentencia de 17 de febrero de 2005, radicación 27673 
que resalta las conexiones que esta figura mantiene con la historia, con otras instituciones básicas de la dogmática administrativista (poder, acto administrativo, contratos, etc.), con las actividades económicas en el mercado y con el modelo constitucional vigente en Colombia para el sector estudiado. En todo caso, esta estructura teórica suscita inquietudes a partir no tanto del concepto de servicio público que propone, sino de las otras definiciones con las que la noción se articula ${ }^{78}$.

En efecto, en la vertiente no autoritativa de la función administrativa, en litigios en los que no se verifique el ejercicio de autoridad, como en la actividad del giro ordinario de cualquier empresa prestadora de servicios públicos, es interesante preguntarse ccómo definir el juez de conocimiento en un litigio con estas características? La respuesta dependerá de cómo lo establezcan las normas procesales correspondientes, pero en ausencia de estas o bajo una normativa poco clara el asunto se vuelve incierto.

Puede pensarse en el caso resuelto por el Consejo de Estado mediante la sentencia de 17 de febrero de 2005, en el que no se enjuiciaban actividades autoritativas por parte de la entidad demandada ${ }^{79}$. De acuerdo con la normativa de ese momento, para asignar competencia al juez de lo contencioso administrativo debía identificarse el ejercicio de función administrativa. Siendo este el caso, acoger la tesis finalista probablemente habría implicado un resultado distinto al que conocimos: el Consejo de Estado habría terminado juzgando actividades de naturaleza comercial que en principio tenían como jurisdicción natural a la ordinaria. Al revisar los planteamientos de la tesis finalista, este resultado no hubiera sido el consecuente con sus premisas teóricas ${ }^{80}$. Ahora bien, como la normativa de ese momento no otorgaba competencia al juez contencioso con base en el ejercicio de prerrogativas públicas, sino con fundamento en el ejercicio de función administrativa, al considerar los servicios públicos una forma de esta función, el desenlace que hipotéticamente se acaba de plantear hubiera sido inevitable: el juez contencioso administrativo conociendo de un asunto ordinario.

78 Conceptos como los de función administrativa, actividad administrativa, actividad administrativa económica y acto administrativo son también desarrollados por Montaña Plata. Alberto Montaña Plata, Fundamentos de derecho administrativo.

79 Sentencia del Consejo de Estado, Sección Tercera, de 17 de febrero de 2005, radicación 50001-23-31-000-2003-00277-01(27673).

80 Con los servicios públicos se sirve a la comunidad, sostiene esta tesis, por lo tanto, se justifica "privilegiar" a los prestadores de servicios públicos, autorizándoles ejercer (excepcionalmente) autoridad para permitir el logro de finalidades públicas. Finalidades que no se desvanecen con la dimensión económica de los servicios públicos y que justifican la procedencia del derecho administrativo para garantizarlas siempre que el derecho común y el mercado no sean suficientes. Alberto Montaña Plata, El concepto de servicio público en el derecho administrativo, pp. 183-184. 
Otra inquietud de interés que surge de esta tesis se relaciona con la aplicación de regímenes de derecho público que proceden, no por verificarse el ejercicio de una función administrativa -autoritativa o no autoritativasino por la presencia de recursos públicos o actividades de interés para el derecho público $(v \cdot g \text {. presupuestal, disciplinario, fiscal })^{81}$. Si se sostiene que el régimen de derecho administrativo procede en la prestación de servicios públicos por el inherente contenido teleológico de tal actividad, quedaría por analizar aquellos casos en los que se aplica derecho público no por el ejercicio de función administrativa -de servicio público-, sino por la presencia de otros criterios de interés para el ordenamiento jurídico.

\subsection{El CONTRASTE ENTRE POSICIONES TEÓRICAS}

\section{Y LAS DUDAS QUE EMERGEN}

De la verificación adelantada emergen varias observaciones a la tesis mayoritaria respecto de la relación función administrativa/servicio público y otras pocas a las otras dos tesis. Estas observaciones se relacionan con: el uso del concepto función administrativa (2.2.1), la definición de la actividad de prestación de servicios públicos (2.2.2), las consecuencias de acoger una u otra definición respecto de los dos institutos anteriores (2.2.3) y los fenómenos que no son protagonistas en las argumentaciones teóricas estudiadas (2.2.4).

\subsubsection{Cuestiones relacionadas con el uso del concepto función administrativa}

La tesis mayoritaria considera la prestación de servicios públicos como una actividad económica desarrollada entre iguales en el libre mercado, regulada por el Estado y sujeta al derecho privado, pero acepta que este régimen jurídico cede el paso al derecho público cuando se rompe la igualdad en esta actividad. Para explicar este tránsito de régimen, la estrategia argumentativa consiste en identificar la función administrativa con el ejercicio de prerrogativas estatales (fenómeno que rompe la igualdad). Se resaltó que una posible explicación para este proceder se encontraba en que la función administrativa operaría como puente para unir el ejercicio de prerrogativas públicas con el régimen de derecho público, en los casos en los que la regla general (servicios públicos $=$ actividad económica $=$ sujetos iguales $=$ derecho privado) no se verificaba.

La tesis finalista puso de manifiesto dos incoherencias de la tesis mayoritaria: la función administrativa ni se reduce al ejercicio de prerrogativas públicas ni impide la procedencia del régimen de derecho privado para 
actividades como la de prestación de servicios públicos liberalizados. Contrario a la tesis mayoritaria, equipara el ejercicio de función administrativa con la prestación de servicios públicos debido al contenido teleológico de esta última actividad y sostiene que tal equiparación no es incompatible con la procedencia general de derecho privado para tal actividad y la presencia excepcional del derecho público en el caso de verificarse prerrogativas públicas. Este contraste teórico deja entonces planteadas dos cuestiones interesantes. Por un lado, la relacionada con la incoherencia interna de la tesis mayoritaria, y por otro lado, la necesidad de explicar la procedencia del régimen de derecho privado para los casos de ejercicio de función administrativa no autoritativa que, además, en no pocos casos también se rige por el derecho público ${ }^{82}$.

\subsubsection{Cuestiones relacionadas con la necesidad de definir la actividad de prestación de servicios públicos}

En las tesis revisadas se hace manifiesta -directa o indirectamente- la necesidad por definir y caracterizar la actividad de prestación de servicios públicos. La tesis mayoritaria y la tesis finalista la consideran una actividad económica relacionada con el interés social, pero mientras la tesis finalista la encuadra en la función administrativa, la mayoritaria no. Para la tesis mayoritaria, el interés público que se predica de los servicios públicos no se desconoce cuando estos son comprendidos como actividad económica porque el diseño institucional permite garantizar todos los intereses en juego en esta actividad. Tanto la libertad de empresa como los derechos de los consumidores, usuarios y ciudadanos se protegen con los mismos mecanismos diseñados para las actividades en libre mercado (regulación ${ }^{83}$, vigilancia y control, protección de la competencia, protección al consumidor, régimen sancionatorio) y mediante su régimen natural: el derecho privado. La tesis finalista no desconoce esta argumentación, pero considera que el contenido teleológico vinculado a tal actividad impide equipararlos a una mera actividad comercial y por ende su naturaleza jurídica se adecúa más a la función administrativa que no se traduce automáticamente en un régimen de derecho público para la actividad, sino solo en aquellos casos en los que se presente el ejercicio de prerrogativas públicas por parte de cualquier prestador. La tesis

82 Sobre este asunto, véase, entre otros, Francisco Velasco Caballero, Derecho público más derecho privado, Madrid: Marcial Pons, 2014.

83 "Como función, la regulación expresa la idea de una mutación de las actuaciones económicas de los actores públicos". ANíBAL ZÁRATE, "La protección constitucional de la rivalidad en el mercado como interés de las actuaciones administrativas en materia económica", p. 637. 
orgánica considera que los servicios públicos son actividades comerciales que dejan de serlo cuando sean prestadas por una entidad pública.

Esta diversidad de posiciones frente a la necesidad de caracterizar la actividad de prestación de servicios públicos demuestra que, aunque se trata de un asunto ampliamente debatido, aún presenta problemas jurídicos que ameritan más desarrollos teóricos que expliquen coherentemente la realidad institucional de este sector en el que convergen múltiples y diversos intereses.

\subsubsection{Cuestiones relacionadas con las consecuencias de asumir una u otra postura frente a las instituciones de la función administrativa y los servicios públicos}

¿Qué consecuencias se generan al asumir una u otra postura frente a los conceptos de función administrativa y de servicio público? El caso Telecom conocido por el Consejo de Estado sirve como ejemplo para pensar en posibles cursos de acción de acuerdo con una u otra escogencia conceptual. Con la hipótesis tal y como ocurrió (se interpretó la prestación del servicio público como una actividad económica libre entre iguales porque no se presentó el ejercicio de función administrativa por no haberse verificado el ejercicio de prerrogativas públicas) fue posible enviar el caso a conocimiento del juez ordinario y de esa manera, confirmar la fórmula del "modelo 1". Otro curso de acción posible pudo haber sido entender a los servicios públicos como una función administrativa. En tal caso, se habría alcanzado un resultado no previsto por la tesis mayoritaria, ni siquiera, por la finalista. Se habría llegado a esta curiosa situación debido a que las normas procesales aplicables en ese momento para resolver el caso identificaban el ejercicio de función administrativa, sin importar sus diversas manifestaciones, como criterio para la procedencia del régimen y control judicial de derecho público. Otro posible curso de acción hubiera sido el propuesto por la tesis orgánica. En ese evento no interesa preocuparse por determinar si la prestación de servicios públicos es o no función administrativa porque, solo debería verificarse si la empresa Telecom podía ser calificada como una entidad pública, en caso afirmativo, el asunto debió haber sido asumido y resuelto por el Consejo de Estado, a pesar de lo extraño que hubiera resultado la presencia de tal especialidad en un litigio con todas las características propias de una típica actividad comercial.

\subsubsection{Cuestiones relacionadas con fenómenos ignorados o superficialmente abordados por las diversas posturas teóricas}

También apareció la cuestión de saber si los criterios funcionales -bien sea concentrarse en el estudio de las actividades económicas o en el estudio de la función administrativa- están presentes de forma exclusiva a la hora de 
configurar y definir el régimen jurídico y de control judicial aplicable a tales actividades. La inquietud surgió al destacarse que la presencia de recursos públicos ${ }^{84} \mathrm{y}$ de intereses estatales considerados especiales ${ }^{85}$ son también tenidos en cuenta, con independencia o sin relevancia exclusiva de la actividad (económica o administrativa), a la hora de diseñar la política legislativa en esta materia y materializar su aplicación. Debido a que las posturas doctrinales revisadas se concentran en sus principales argumentos (las prerrogativas públicas, la presencia de una entidad pública, el carácter teleológico de la actividad), estas cuestiones son ignoradas o no suficientemente estudiadas $y$, por consiguiente, se pierde la oportunidad para ser tenidas en cuenta e integradas coherentemente en los debates argumentativos ${ }^{86}$.

Estos cuatro interrogantes bien pueden resumirse en dos grandes asuntos: por un lado, la cuestión de la definición de los conceptos utilizados para operar en el sistema jurídico y, por otro lado, el asunto de las consecuencias que se derivan de contar o no con instituciones previamente definidas antes de resolver problemas jurídicos. Estas dos cuestiones, a su vez, pueden ser evaluadas con una medida: ausencia o presencia de coherencia interna en las tesis que intentan resolver los problemas sociales de forma argumentada

84 Bajo este criterio y con independencia de cualquier otra consideración, es posible nombrar la procedencia de las reglas de tres áreas esenciales del derecho público: el derecho disciplinario, el derecho fiscal y el derecho presupuestal. Un ejemplo de política legislativa que se centra en un interés especial, relacionado con el objetivo de proteger recursos públicos, puede ser el del supuesto contenido en el parágrafo del artículo 31 de la Ley 142 de 1994, sobre "contratos que celebren los entes territoriales con las empresas de servicios públicos con el objeto de que estas últimas asuman la prestación de uno o de varios servicios públicos domiciliarios, o para que sustituyan en la prestación a otra que entre en causal de disolución o liquidación".

85 En la argumentación de algunas de las sentencias estudiadas son evidentes ciertas dificultades, no solo para comprender jurídicamente actividades que se califican como servicios públicos (v.gr. administración de justicia, servicios notariales, actividad bancaria, servicios de salud), sino para integrarlas coherentemente en un modelo de servicios públicos en el que parecen no encajar. Cfr. sentencias C-574 de 2003, T-763 de 2005, C-957 de 2007 y C-368 de 2011. Reflexiones en este sentido también son procedentes para los casos en los que, actividades como la "fuerza pública" son consideradas como servicios públicos. Cfr. sentencia de la Corte Constitucional T-578 de 1992. En un sentido similar, de acuerdo con lo consagrado en el artículo 39.1 de la Ley 142 de 1994, la protección de los recursos naturales también es un criterio que hace procedente el régimen de derecho administrativo en la prestación de servicios públicos.

86 Una investigación sobre la interacción entre la función y la estructura, más allá de una mera perspectiva mixta o ecléctica, ha comenzado a ensayarse por el autor en RONALD PaCHeCo-Reyes, "How do Rights Become Probable in the Global Context?", Liverpool Law Review, 2021. También Niklas Luhmann, El derecho de la sociedad; ERneSt WeInRIB, The Idea of Private Law, Oxford: Oxford University Press, 2012; Fernando AtRia, La forma del derecho, Madrid: Marcial Pons, 2016. 
(dogmática jurídica ${ }^{87}$. Entre mayor coherencia teórica, es más probable que el sistema jurídico pueda cumplir su función de garantizar las expectativas normativas de los sujetos de derecho.

\section{CONCLUSIONES}

El examen de las diversas tesis muestra un importante desarrollo teórico, aunque también evidencia que persisten importantes asuntos jurídicos que investigar. En concreto, aunque existe una tesis mayoritaria que distingue la función administrativa de los servicios públicos, esta postura presenta incoherencias relevantes como, por ejemplo, identificar el ejercicio de función administrativa con prerrogativas públicas ${ }^{88}$. Por su parte, la tesis orgánica simplifica excesivamente el sector de los servicios públicos al hacer depender la calificación y el régimen de este fenómeno de la calidad del sujeto que los preste. De otro lado, la tesis finalista, aunque presenta un alto grado de coherencia interna, parece depender de la existencia de normas de derecho positivo concreto para resolver aspectos procesales por cuanto la función administrativa puede ser o no autoritativa, y puede regirse o no regirse bajo las reglas del derecho privado. Esta conclusión permite responder la cuestión planteada en la parte introductoria del escrito señalando que, a pesar de los importantes avances en el tratamiento dogmático de la problemática, se justifica continuar buscando coherencia teórica.

Desde luego, para que una incoherencia teórica se presente, no es necesario que se evidencie un error craso en determinada postura. Basta con una comprensión jurídica distinta de un concepto que no esté soportada con una debida argumentación contrastada con la realidad del caso concreto para generar desorden e incertidumbre en el sistema jurídico. Incluso, puede suceder que la conclusión de una tesis jurídica sea coincidente con una exigencia política, sin embargo, esta convergencia no exime a los operadores jurídicos del deber de llegar a sus conclusiones atendiendo la racionalidad propia del campo en el que desempeñan sus roles ${ }^{89}$.

87 En relación con esto, Luhmann sostiene que "la dogmática deberá entenderse como expresión de la necesidad del argumentar en el derecho, mediante conceptos; o como el aseguramiento del concepto frente a la ilimitada cuestionabilidad jurídico-política ${ }_{i}$ es decir: una regla de demarcación frente a un razonar permanente en busca de fundamento". NikLas LuhmanN, El derecho de la sociedad, p. 276.

88 Cabe recordar que la Corte Constitucional -luego de la sentencia C-037 de 2003- ha equiparado función administrativa y servicio público, no con fundamento en prerrogativas públicas, sino en el "carácter especial" de esta última actividad.

89 Una de las premisas de la teoría de sistemas sociales de Luhmann es la diferenciación funcional que implica que cada sistema tiene una función distinta que no comparte con 
Está claro que la Constitución de 1991 establece un nuevo modelo de servicios públicos, liberalizado, en el que su prestación debe desarrollarse en condiciones igualdad y régimen jurídico privado. Pero la existencia de esta premisa no implica su aplicación directa y "a toda costa", entre otras cosas, porque habrá de estudiarse si el caso concreto es de aquellos que encajan en el modelo constitucional, cuestión para nada sencilla teniendo en cuenta que bajo la noción de "servicios públicos" se sigue etiquetando en el derecho colombiano una diversidad de fenómenos que pueden ir desde las actividades típicas administrativas -incluso estatales- hasta actividades característicamente comerciales ${ }^{90}$. Esto exige tener precauciones frente a las generalizaciones, pero sobre todo exige continuar buscando la coherencia entre los conceptos función administrativa y servicios públicos, porque ¿qué tan sólida puede ser una diferencia entre dos instituciones jurídicas que aun no son definidas con claridad?

\section{BIBLIOGRAFÍA}

\section{DOCTRINA}

Alexy, Robert. Teoría de la argumentación jurídica. Lima: Palestra, 2007.

Atehortúa Ríos, Carlos Alberto. Servicios públicos domiciliarios, proveedores y régimen de controles. Bogotá: Universidad Externado de Colombia, 2006.

Atienza, Manuel. Las razones del derecho. Teorías de la argumentación jurídica. México: Universidad Nacional Autónoma de México, 2005.

Atria, Fernando. La forma del derecho. Madrid: Marcial Pons, 2016.

otro. Si bien a Luhmann no le interesan los discursos morales, no pretende declarar cómo deben ser las cosas; con su teoría social deja en evidencia que una des-diferenciación implica situaciones que en algunos contextos se traducen en actos de corrupción, como, por ejemplo, cuando se resta importancia a la autonomía del derecho y se pretende de este sistema que produzca decisiones importando órdenes de la política o la economía. Sobre el peligro de la des-diferenciación, véase NiKLAS LuHMANN, Los derechos fundamentales como institución. Aportación a la sociología política, México: Universidad Iberoamericana, 2010, pp. 99 y ss.

90 Como ejemplo interesante, vale la pena tener en cuenta que, en su momento, frente a este mismo problema, en el derecho europeo se tuvo que adicionar un nuevo aparato conceptual para enfrentar la complejidad que implica el ejercicio de actividades comerciales que son de interés general y que se relacionan con diversas tradiciones jurídicas. Véase Tony Prosser, "Services of General Interest, the Commission, and Reform", en The Limits of Competition Law: Markets and Public Services, Nueva York: Oxford, 2005, pp. 153 y ss. 
Bauby, PIerre, et al. "Introducción general". En Pierre Bauby, Henri de Coing y Alain Tolédo, Los servicios públicos en Europa. Hacia una regulación democrática. Bogotá: Universidad Externado de Colombia, 2010.

Cajarville, Juan Pablo. "Hauriou, Duguit y la noción de servicio público en el derecho público uruguayo". En Andry Mantilla Correa, Jaime Santofimio Gamboa y Héctor Orlando Santaella Quintero (coords.), Ensayos de derecho público. En memoria de Maurice Hauriou. Bogotá: Universidad Externado de Colombia, 2013.

Carvajal SÁnchez, Bernardo. "Avatares del servicio público en el derecho administrativo colombiano". En Las transformaciones de la administración pública y del Derecho administrativo, t. I, Constitucionalización de la disciplina y evolución de la actividad administrativa. Homenaje al profesor Luciano Vandelli. Bogotá: Universidad Externado de Colombia, 2019 [eBook].

Castaño Parra, Daniel. "Estudio introductorio". En Alberto Montaña Plata y Daniel Castaño Parra (comps.), Régimen normativo de los servicios públicos domiciliarios: Ley 142 de 1994, disposiciones complementarias y jurisprudencia de constitucionalidad concordada. Bogotá: Universidad Externado de Colombia, 2010.

Christiano, Thomas. "The Authority of Democracy". The Journal of Political Pbilosopby, vol. 12, n. ${ }^{\circ} 3,2004$

COVILla Martínez, JuAN CARLOS. Autorizaciones y concesiones en el derecho administrativo colombiano. Bogotá: Universidad Externado de Colombia, 2014.

Díez Sastre, Silvia, y Ester Marco PeÑas. "La convergencia de las reglas de contratación pública y disciplina presupuestaria en el sector público instrumental". Revista Española de Derecho Administrativo, n. ${ }^{\circ} 205,2020$.

Duguit, LEON. Las transformaciones del derecho público. Madrid: Francisco Beltrán, 1926.

FERnÁNDEZ, TOMÁS-RAMÓN. "Del servicio público a la liberalización desde 1950 hasta hoy". Revista de Administración Pública, n. ${ }^{\circ}$ 150, 1999, pp. 57-73.

FORSTHOFF, ERNST. Tratado de derecho administrativo. Madrid: Instituto de Estudios Políticos, 1958.

Giannini, Massimo S. Derecho administrativo, vol. I. Madrid: Ministerio para las Administraciones Públicas, 1991.

Gimeno Feliú, José María. "Las fronteras del contrato público: depuración conceptual de los negocios jurídicos excluidos desde la perspectiva funcional del Derecho europeo". Revista Española de Derecho Administrativo, n. ${ }^{2}$ 205, 2020. 
Gottlieb, Paula. "Aristotle on Non-contradiction". En The Stanford Encyclopedia of Pbilosopby, 2019. Recuperado de https://plato.stanford.edu/archives/spr2019/ entries/aristotle-noncontradiction/

Green, LeSLIE. The authority of the State. Oxford: Clarendon Press, 1988.

Hart, Herbert. The Concept of Law. Oxford: Oxford University Press, 1994.

Hauriou, Maurice. Précis de droit administratif et de droit public, 8. ${ }^{\text {a }}$ ed. París: Sirley, 1914.

LOZANO VilleGAS, GERMÁN. "La función administrativa ejercida por particulares en Colombia". En Entidades privadas colaboradoras de la administración. Valencia: Tirant lo Blanch, 2020.

LuhmanN, NiKLaS. El derecho de la sociedad. México: Herder, 2016.

LUHMANN, NiKLAS. Los derechos fundamentales como institución. Aportación a la sociología política. México: Universidad Iberoamericana, 2010.

Luhmann, Niklas. Sistema jurídico y dogmática jurídica. Madrid: Centro de Estudios Constitucionales, 1983.

MCNabb, David. Public Utilities. Cheltenham: Edward Elgar, 2005.

Montaña Plata, Alberto. "La desconfiguración del régimen jurídico de los servicios públicos domiciliarios a partir de la calificación de entidades públicas a las empresas de servicios públicos mixtas". Revista digital de Derecho Administrativo, n. ${ }^{\circ} 3,2010$, pp. 163-190.

Montaña Plata, Alberto. "El régimen normativo de la responsabilidad contractual en los servicios públicos domiciliarios. Configuración teórica de las prerrogativas públicas y protección del capital en consideración con su destinación". En Memorias IV Jornadas de Derecho Constitucional Administrativo. El régimen de las libertades. La responsabilidad de la Administración pública. Bogotá: Universidad Externado de Colombia, 2003.

Montaña Plata, Alberto. El concepto de servicio público en el derecho administrativo. Bogotá: Universidad Externado de Colombia, 2005.

Montaña Plata, Alberto. Fundamentos de derecho administrativo. Bogotá: Universidad Externado de Colombia, 2010.

Montaña Plata, Alberto. Las transformaciones de la Administración pública y del derecho administrativo, t. I, Constitucionalización de la disciplina y evolución de la actividad administrativa. Homenaje al profesor Luciano Vandelli. Bogotá: Universidad Externado de Colombia, 2019. 
Montaña Plata, AlBerto. Los grandes fallos de la jurisprudencia administrativa colombiana. Bogotá: Universidad Externado de Colombia, 2013

Moreno, LUIS FerneY. "Los servicios públicos y su permanencia como institución jurídica en Colombia". En Teoría de los servicios públicos. Lecturas seleccionadas. Bogotá: Universidad Externado de Colombia, 2018

NúÑ̃EZ FORERO, FELIPE. Servicios públicos domiciliarios, telecomunicaciones e infraestructura (instituciones, regulación y competencia). Bogotá: Universidad Externado de Colombia, 2017.

Pacheco-Reyes, Ronald. "How do Rights Become Probable in the Global Context?". Liverpool Law Review, 2021.

PACHECO-Reyes, Ronald. Televisión y nuevas realidades tecnológicas y de mercado. Hacia el sistema de la comunicación audiovisual. Bogotá: Universidad Externado de Colombia, 2017.

Palacios Mejía, Hugo. El derecho de los servicios públicos. Bogotá: Derecho Vigente, 1999.

Pérez Bermejo, Juan Manuel. Coberencia y sistema jurídico. Madrid: Marcial Pons, 2006

Peter, Fabienne. "Political Legitimacy". En The Stanford Encyclopedia of Pbilosopby, 2017. Recuperado de https://philpapers.org/rec/petpl

Prosser, TOny. "Services of General Interest, the Commission, and Reform". En The Limits of Competition Law: Markets and Public Services. Nueva York: Oxford, 2005.

RaZ, Joseph. The Authority of Law. Essays on Law and Morality. Oxford: Clarendon Press, 1979.

Rincón CÓRDOBA, JORGE IVÁN. Derecho administrativo laboral: Empleo público, sistema de carrera administrativa y derecho a la estabilidad laboral. Bogotá: Universidad Externado de Colombia, 2009.

RINCÓN CÓRDOBA, JORGE IVÁN. La teoría de la organización administrativa en Colombia. Bogotá: Universidad Externado de Colombia, 2018.

SAnTAElla Quintero, HÉCTOR. "Algunas reflexiones sobre las nuevas formas de actuación administrativa impuestas por el mercado y la técnica y sus implicaciones para la metodología de la ciencia jurídica-administrativa". Revista digital de Derecho Administrativo, n. ${ }^{\circ}$ 5, 2011. 
Santaella Quintero, HéCTOR. Normas técnicas y derecho en Colombia: Desafíos e implicaciones para el derecho en un entorno de riesgo. Bogotá: Universidad Externado de Colombia, 2008.

SCHMIDT-ASSMANN, EBERHARD. La teoría general del derecho administrativo como sistema. Madrid: Marcial Pons, 2003.

SCHWEITZER, HEIKE. "Services of General Economic Interest: European Law's Impact on the Role of Markets and of Member States". En Marise Cremona, Market Integration and Public Services in the European Union. Oxford: Oxford University Press, 2011.

Velasco Caballero, Francisco. Derecho público más derecho privado. Madrid: Marcial Pons, 2014.

Vergara Mesa, Hernán. "La función administrativa: Una mirada desde el derecho colectivo al acceso y eficiente prestación de los servicios públicos". Estudios de Derecho, vol. 66, n. ${ }^{\circ} 148,2009$.

Weinrib, Ernest. The Idea of Private Law. Oxford: Oxford University Press, 2012.

ZÁRATE, ANíBAL. "La protección constitucional de la rivalidad en el mercado como interés de las actuaciones administrativas en materia económica". En Jorge Iván Rincón (ed.), Las transformaciones de la administración pública y el derecho administrativo, t. I, Constitucionalización de la disciplina y evolución de la actividad administrativa. Bogotá: Universidad Externado de Colombia, 2019.

\section{JURISPRUDENCIA}

\section{Corte Constitucional}

Sentencia T-578 de 1992, de 3 de noviembre de 1992, expediente T-1848.

Sentencia C-041 de 1995, de 9 de febrero de 1995, expediente D-796.

Sentencia C-075 de 1997, de 20 de febrero de 1997, expediente D-1400.

Sentencia C-741 de 1998, de 2 de diciembre de 1998, expediente D-2139.

Sentencia T-001 de 1998, de 16 de enero de 1998, expediente T-142712.

Sentencia T-617 de 1998, de 28 de octubre de 1998, expediente T-169767.

Sentencia T-638 de 1998, de 4 de noviembre de 1998, expediente T-179381.

Sentencia T-693 de 1999, de 16 de septiembre de 1999, expediente T-220705. 
Sentencia C-474 de 1999, de 7 de julio de 1999, expediente D-2274.

Sentencia C-830 de 2001, de 8 de agosto de 2001, expediente D-3368.

Sentencia C-109 de 2002, de 20 de febrero de 2002, expediente D-3562.

Sentencia C-037 de 2003, de 28 de enero de 2003, expediente D-3982.

Sentencia C-574 de 2003, de 15 de julio de 2002, expediente D-4462.

Sentencia T-763 de 2005, de 21 de julio de 2005, expediente T-1079385.

Sentencia C-957 de 2007, de 14 de noviembre de 2007, expediente D-6813.

Sentencia C-378 de 2010, de 19 de mayo de 2010, expediente D-7940.

Sentencia C-368 de 2011, de 11 de mayo de 2011, expediente D-8245.

Sentencia C-185 de 2019, de 8 de mayo de 2019, expediente D-12890.

\section{Consejo de Estado}

Sentencia de la Sala de lo Contencioso Administrativo, Sección Tercera, 5 de agosto de 1999, radicado ACU-798.

Sentencia de la Sala de lo Contencioso Administrativo, Sección Quinta, 19 de febrero de 2004, radicación 25000-23-25-000-2003-1843-01(ACU).

Sentencia de la Sala de lo Contencioso Administrativo, Sección Tercera, 13 de mayo de 2004, radicación 50001-23-31-000-2003-00020-01(AP).

Sentencia de la Sala de lo Contencioso Administrativo, Sección Tercera, 10 de febrero de 2005, radicación 25000-23-25-000-2003-00254-01(AP).

Sentencia de la Sala de lo Contencioso Administrativo, Sección Tercera, 17 de febrero de 2005, radicación 50001-23-31-000-2003-00277-01(27673).

Sentencia de la Sala de lo Contencioso Administrativo, Sección Tercera, 15 de agosto de 2007, radicación 88001-23-31-000-2005-00004-01(AP).

Sentencia de la Sala de lo Contencioso Administrativo, Sección Cuarta, 30 de marzo de 2016, radicación 47001-23-31-000-2011-00133-01(19960). 